\title{
Luchas por el control territorial en Colombia
}

\author{
DARÍO I. ReSTREPO*
}

\begin{abstract}
The main thesis of the paper is that concurrence of globalization impacts, decentralization processes and political crisis seriously weaken the role of the National State, particularly as they break the basis of political, administrative and economical centralism. On the other hand, local struggles for material resources and institutional control are exacerbated. Therefore, the local political negotiation power increases compared to the central government one, same about the decentralized functions than about the ones that are state-centered and centralized. Neoliberals, political reformers, political territorial classes, new social movements, drug traffickers, guerrillas and paramilitars openly dispute local power. All of them have a strategy, or at least a set of interests and practices about the decetralization process, which can be understood only as a result of the complexity of forces that acts on it.
\end{abstract}

Keywords: local power, neoliberalism, political reformists, new social movements, guerrilla, paramilitars, drug traffickers.

\section{Resumen}

La tesis central del artículo es que la concurrencia entre los impactos de la globalización, el proceso de descentralización y la crisis política debilitan gravemente el Estado-Nación, y particularmente tienden a romperse las bases mismas del centralismo político, administrativo y económico. Por otra parte, se exacerban las luchas locales por la apropiación de las riquezas materiales y el control de las instituciones. De esta manera, se acrecienta el poder de negociación política de las fuerzas locales frente al gobierno central, tanto respecto de las funciones descentralizadas como de aquellas que mantiene el Estado de manera centralizada. Neoliberales, reformadores políticos, clases políticas territoriales, nuevos movimientos sociales, narcotraficantes, guerrilleros y paramilitares se disputan abiertamente el poder local. Todos tienen una estrategia, o al menos un conjunto de intereses y prácticas respecto del proceso de descentralización, el cual en última instancia no puede ser entendido sino como el resultado de la complejidad de fuerzas que intervienen en él.

Palabras clave: Poder local, neoliberalismo, reformadores políticos, nuevos movimientos sociales, guerrilla, paramilitares, narcotraficantes.

*Universidad Nacional de Colombia. Correo-e: direstre@colomsat.net.co 


\section{Introducción ${ }^{1}$}

Uno de los aspectos más importantes de la reforma del Estado en Colombia es sin duda el proceso de descentralización con sus tres componentes: el político, con la elección de gobernadores departamentales y alcaldes municipales; el administrativo, con la delegación de las políticas sociales básicas a los gobiernos locales, y el fiscal, con la transferencia de $46 \%$ de los ingresos corrientes de la nación a las entidades territoriales.

El proceso de descentralización ocurre de manera concomitante a la apertura e internacionalización de la economía. La descentralización tiene, junto con la apertura, una consecuencia común: el debilitamiento del Estado-Nación, al tiempo que se fortalecen las esferas internacional y local en los procesos económicos y políticos. Ambos procesos ocurren en un escenario de crisis del régimen político y de graves enfrentamientos armados en el país y ponen a prueba la supervivencia del Estado-Nación colombiano.

Situar el proceso de descentralización en perspectiva implica relacionarlo con el cambio en el modelo de desarrollo y la crisis política. Respecto de estas transformaciones generales, el conjunto de actores políticos, económicos, burocráticos, gremiales, sindicales, populares e insurgentes adapta sus estrategias de promoción de intereses. Ello hace imperativo estudiar el proceso de descentralización en tanto negociación entre actores, intereses y racionalidades contradictorias.

La tesis central que desarrolla el trabajo es que la concurrencia entre los impactos de la globalización, el proceso de descentralización y la crisis política debilitan gravemente el EstadoNación, y particularmente se tiende a romper las bases del centralismo político, administrativo y económico. Por otra parte, se exacerban las luchas locales por la apropiación de las riquezas materiales y el control de las instituciones. De esta manera, se acrecenta el poder de negociación política de las fuerzas locales frente al gobierno central, tanto respecto de las funciones descentralizadas como de aquellas que mantiene el Estado de manera centralizada.

\footnotetext{
${ }^{1}$ Versión parcial y corregida de un trabajo más extenso presentado en el vi Seminario de la Red Iberoamericana de Investigadores sobre Globalización y Territorio, bajo el título: Descentralización o desintegración del Estado, 1970-2000. Agradezco la asistencia de investigación de Néstor Castañeda.
} 
Este es el escenario en que se desenvuelve la guerra política y respecto del cual una eventual salida negociada al conflicto armado pasará necesariamente por una redistribución del poder regional y nacional en el país; particularmente, requerirá una nueva organización espacial del régimen político y electoral, de las políticas y del gasto público y, finalmente, de las competencias y soberanías de los diferentes niveles territoriales del Estado (Castañeda, González y Mares, 2000).

\section{La estrategia neoliberal y la imposición del mercado por la vía de la descentralización}

La tecnocracia neoliberal tiene una preocupación básica acerca de la eficiencia del Estado. Sostiene que es ineficiente porque a mayor cantidad de gasto, funcionarios, instituciones y programas públicos no le corresponde un crecimiento de territorios y población cubierta por los servicios, ni un incremento en la cantidad o calidad de éstos.

Según ese enfoque se deben impulsar reformas a partir de tres principios: (1) que el Estado se comporte exactamente como el sector privado, el cual se supone eficiente; (2) privatizar el máximo de funciones y empresas estatales, y (3) aquellas funciones y recursos que quedan a cargo del Estado deben ser lo más permeable posible a las leyes del mercado (Bird, 1981; Wiesner, 1992).

Es por ello que los neoliberales tienen interés en la descentralización, pues suponen que facilita los procesos de privatización e induce los procesos regidos por el mercado en el manejo del Estado, de las siguientes maneras:

La descentralización debe estimular la competencia de los gobiernos locales por los recursos transferidos. Lo anterior se refleja en el hecho de que $16 \%$ de las participaciones de los municipios en los ingresos corrientes de Colombia está condicionado a la obtención de desempeños fiscales, administrativos y de reducción de la pobreza. ${ }^{2}$ También se expresa en la cultura de proyectos, la técnica de focalización de beneficiarios de la inversión pública y los subsidios a la demanda. ${ }^{3}$ En todos los casos, se

\footnotetext{
${ }^{2}$ Ley 60 de 1993 que reguló, hasta la Ley 715 de diciembre de 2001, la repartición de recursos y funciones entre niveles territoriales.

${ }^{3}$ Estas técnicas de asignación del gasto público caracterizan el conjunto de las inversiones realizadas por la nación en los territorios, mediante fuentes financieras paralelas a los recursos transferidos mediante las leyes de descentralización.
} 
someten bolsas de recursos a la competencia entre entidades territoriales. De esta manera, se combate la lógica de repartición de los recursos a los territorios por relaciones políticas al interior de los partidos políticos o del Congreso de la República, por presiones sociales o derechos adquiridos. A cambio, se estimula la distribución de recursos por la competencia, el mérito y el desempeño de unas entidades territoriales sobre otras ${ }^{4}$ (Restrepo, 2001).

En segundo lugar, se usa el proceso de descentralización para promover la privatización de las funciones y empresas del Estado. Es así como las leyes de descentralización de servicios públicos domiciliarios, de la salud, la educación y las vías, son todas leyes de privatización. ${ }^{5}$ Además, se transfiere a los gobiernos locales unas competencias y unos recursos, pero estos últimos son menores que los costos reales de asumir las competencias. De esta manera, los gobiernos locales se ven obligados a aumentar el cobro de las tarifas de los servicios públicos y la tributación local, así como emprender la privatización de las empresas. En los últimos seis años buena parte de los gobiernos locales de Colombia han convocado subastas públicas para vender las empresas descentralizadas, muchas de ellas compradas por capitales transnacionales (Cuervo y González, 1998; Maldonado, 1998; Restrepo, 2000).

La participación de los gobiernos locales en los costos financieros y políticos de la administración de los servicios es un objetivo estratégico. El imperativo neoliberal, formulado desde la década de los 50 en Europa y en los Estados Unidos de Norteamérica, y apropiado por la élite criolla en la década de los 70, es el siguiente: es necesario superar definitivamente una situación que conduce a un aumento creciente de las demandas sociales sobre el presupuesto nacional en un escenario de incapacidad financiera y administrativa de los Estados para proveer esas demandas. Se trata de superar la lógica que conduce a que toda reivindicación social, falencia o carencia en el bienestar, en las necesidades básicas insatisfechas y en el desarrollo se convierta en una demanda al Estado central y por tanto al presupuesto nacional. Para lograr el objetivo, se transfieren la responsabilidad y la financiación de las políticas sociales básicas a los gobiernos

\footnotetext{
${ }^{4}$ Para los neoliberales, la competencia debería ser similar a la que ocurre entre empresas privadas en el mercado. En la práctica se genera una combinación con la competencia que los políticos emprenden por hacerse al mercado de los bienes públicos.

${ }^{5}$ Dichas leyes fueron promulgadas durante el gobierno del presidente César Gaviria (1990-1994), reconocido por el 'revolcón' neoliberal que introdujo en el país.
} 
locales, con lo cual se pretende "localizar" el malestar social y "blindar" el presupuesto central contra las tendencias deficitarias (Velázquez, 1986).

Del objetivo anterior se desprende el siguiente: forzar al consumidor a pagar el precio real de los bienes públicos, es decir, desmontar el sistema de subsidios. ${ }^{6}$ Para los neoliberales, el Estado es ineficiente porque subsidia los precios finales; en cambio, el sector privado es eficiente porque cobra el costo real más un porcentaje correspondiente a las ganancias promedio de la actividad económica en cada rama productiva o comercial específica. Para que el Estado sea eficiente debe cobrar también los precios reales y ello se logra mediante la descentralización de la responsabilidad a los gobiernos locales. Estos últimos están abocados por la vía de la privatización, o cuando la función sigue de responsabilidad estatal- a cobrar los precios reales de los bienes y servicios producidos (González, 1994). Los grandes consumidores de las políticas públicas descentralizadas, básicamente la salud y la educación, son las clases medias y los sectores populares. De esta manera, el neoliberalismo está logrando que las clases populares paguen más impuestos, mayores tarifas y participen en la ejecución de las obras, generando un ahorro al Estado y transfiriendo el costo de los bienes básicos a los consumidores (Beck, 1998; Restrepo, 2000).

La descentralización dentro de la estrategia privatizadora promueve la competencia entre las empresas públicas y privadas, es decir, rompe los monopolios estatales sobre la prestación de bienes y servicios. A cambio, promueve la competencia entre empresas del Estado y del sector privado bajo el supuesto de que sólo la igualdad en la competencia traerá mayores niveles de eficiencia (Banco Mundial, 1993; Jaramillo, 1994).

Según la ideología neoliberal, el consumidor es el soberano en el mercado privado. La mayor inquietud es lograr que también lo sea respecto de los bienes que ofrece el mercado estatal. La solución encontrada reside en el pago de los precios reales y en el aumento de la capacidad de sanción del consumidor sobre los mandatarios, los funcionarios, los presupuestos y las políticas públicas (Wiesner, 1992; Rosas, 1997).

\footnotetext{
${ }^{6}$ No sobra señalar que la presión tributaria en las últimas décadas recae sobre los impuestos indirectos al consumo y sobre los salarios. Esta práctica impositiva tiene un efecto regresivo en cuanto al logro de la equidad entre estratos sociales por nivel de ingresos, a diferencia del efecto sobre la equidad que acarrea cobrar mayores impuestos directos proporcionales a las ganancias, el capital y la renta.
} 
La exacta correspondencia entre el desarrollo de las instituciones y los mercados es la respuesta adecuada a la pregunta sobre el óptimo del tamaño del Estado y del gasto público deseable. Según su diagnóstico, el Estado creció en gasto, instituciones, burocracia y programas, a un punto que no corresponde a la realidad de los mercados, es decir, por encima de lo que la sociedad en su conjunto está generando como ingresos para sostenerlo. Se generalizó así la subvención de las políticas sociales mediante el déficit fiscal que presiona un alza en la tributación al sector privado y reduce sus márgenes de ganancia. En consecuencia, los neoliberales tratan de adecuar las instituciones a la capacidad de los mercados, para lo cual impulsan la privatización y la descentralización con el fin de que la dimensión de las instituciones corresponda exactamente a lo que los mercados locales puedan financiar a través del cobro de los servicios y de la política tributaria local (Wiesner, 1992).

Como conclusión, el neoliberalismo tiene como estrategia aumentar el peso del mercado, los agentes privados y los consumidores en las políticas públicas. También presiona una conversión de los políticos en gerentes y administradores, es decir, inducen la desideologización de la política para lograr el cese del enfrentamiento ideológico sobre opciones éticas, morales, sociales o de clases sociales. A cambio, promueven una competencia entre administradores de recursos y servicios públicos. Por lo tanto, para la estrategia neoliberal, la descentralización es un componente fundamental de su política.

\section{Los reformadores políticos incluyentes: "descentralizar para pacificar"7}

El neoliberalismo no es la única fuerza que explica el acontecer del proceso de descentralización en Colombia, ni en ningún otro país de América Latina. Consideramos bajo el calificativo de reformadores políticos a una fracción importante de la clase política, líderes empresariales y sociales que buscan una solución socialmente 'incluyente' a la crisis política y económica por la que atraviesan nuestros países (Santamaría y Silva, 1984).

${ }^{7}$ Descentralizar para pacificar es el título de un libro de Jaime Castro (1998), ex alcalde de la ciudad de Bogotá, ex ministro de gobierno y ex constituyente que impulsó el primer paquete legislativo integral del proceso de descentralización en 1986. Castro también participó en los acuerdos de tregua firmados con las Fuerzas Armadas Revolucionarias de Colombia (FARC) en 1984 y 1985. 
En Colombia, dicha inclusión abarca al movimiento insurgente que tiene presencia en más de $40 \%$ del territorio nacional. Jaime Castro reconoce que el mapa de la insubordinación civil y de la insurgencia armada corresponde al mapa de la ausencia y la precariedad del Estado en el territorio nacional. Donde el Estado no está, es decir, donde sus instituciones, las políticas sociales, el crédito y el gasto en infraestructura son precarios y donde el control de los partidos políticos es frágil se presenta en mayor medida la insubordinación social a través de paros, marchas y tomas, y prevalece la insurgencia armada. Desde esta perspectiva se planteó la construcción de unas instituciones capaces de integrar y abrir compuertas dentro del sistema representativo y de las políticas públicas a esos sectores 'excluidos' y llevar recursos, infraestructura y programas estatales a los territorios de gran precariedad estatal (Castro, 1984).

Los reformadores políticos buscaron abrir la carta política y electoral del país mediante el proceso de descentralización. En términos del ex presidente Belisario Betancur (1982-1986) existían "causas objetivas y subjetivas" para la violencia en Colombia. La causa objetiva se refiere a la pobreza, el abandono y la marginalidad de millones de personas; la causa subjetiva, al régimen político llamado Frente Nacional, a través del cual dos partidos, el liberal y el conservador, se repartieron mediante amparo constitucional los cargos representativos y administrativos del Estado. ${ }^{8}$ Desde el tiempo del presidente Betancur se inauguró una tendencia a descentralizar recursos para llevar los servicios sociales básicos a todos los municipios del país, y también se promulgó la elección popular de alcaldes para insertar todas las fuerzas sociales y políticas existentes dentro del régimen político representativo (Ochoa y Restrepo, 1997).

${ }^{8}$ El régimen político del Frente Nacional ha atravesado varias etapas. La primera, entre 1958 y 1974, implantó la plena dictadura bipartidista sobre el Estado mediante la repartición paritaria de los cargos y presupuestos, la rotación de la función presidencial entre los dos partidos, liberal y conservador, y el carácter 'nacional', es decir bipartidista, del gobierno. En la segunda etapa, de 1974 a 1986, amainó el acuerdo y se introdujo la competencia electoral en la rama legislativa en los ámbitos municipal, departamental y nacional, así como la libre contienda para la elección del presidente. El gobierno nacional siguió representando el Frente Nacional mediante una repartición 'adecuada y equitativa' entre los dos partidos en la rama ejecutiva, así como el Estado mantuvo la impronta 'frentenacionalista' mediante la designación de los altos dignatarios de las ramas públicas a todo nivel de la administración, dentro de los partidos tradicionales. La tercera etapa comenzó con la elección de alcaldes en 1986 y todavía no concluye. A pesar de la existencia de la competencia electoral a todo nivel y para todos los cargos ejecutivos y legislativos, el bipartidismo decadente mantiene control sobre los altos cargos públicos. 
En particular se pensó en las fuerzas políticas y sociales locales que no tenían una fuerza nacional suficiente para estar representadas en el Congreso de la República y que tampoco participaban en la definición, por las vías legales, de los procesos políticos locales. La descentralización buscó, entonces, abrir el mapa electoral colombiano mediante la integración de aquellos que estaban afuera del régimen político del Frente Nacional y de las mayorías bipartidistas en el ámbito nacional. ${ }^{9}$

El objetivo político fue también social y económico, puesto que estos reformadores buscaban descentralizar el modelo de desarrollo, haciendo llegar recursos ahí donde no llegaban con anterioridad, con lo cual se estimularía el desarrollo de los mercados locales y regionales y la integración nacional.

La descentralización permitió, además, la reconducción de las politicas sociales estatales hacia grupos de pobladores vulnerables. La anterior política social en salud, educación, vivienda y seguridad social estaba dirigida de manera predominante al asalariado. El sector informal y rural eran 'atendidos' mediante programas aleatorios de carácter nacional -como hasta ahora- y mediante la extensión de las redes de servicios clientelistas que llevan las políticas sociales a los sectores pobres como mecanismo fundamental de reproducción de los partidos tradicionales.

Los reformadores políticos incluyentes buscaban descentralizar recursos hacia la población no asalariada y más vulnerable: los pobres, las mujeres cabeza de hogar, las etnias, los indígenas, las negritudes, los poblados sin apoyo estatal y precario desarrollo del mercado y las poblaciones en zonas de desastre natural o víctimas de la violencia: es decir, la población que no se define por sus relaciones salariales o que en buena medida no es asalariada. La nueva política social especializa su intervención por sectores sociales, que a su vez están localizados en territorios y situaciones específicas. Asimismo, acude de manera creciente a la responsabilidad de los gobiernos locales en la implantación de las campañas de lucha contra la pobreza y en favor de grupos vulnerables específicos (Restrepo, 1996).

La descentralización de la política social y el interés por la población pobre y vulnerable viene aparejado con el crecimiento de los mecanismos de participación social y politica dentro de las instituciones, las administraciones públicas locales y los progra-

\footnotetext{
${ }^{9}$ Los acuerdos de cese al fuego en 1984-1985 entre el gobierno nacional y las FARC apoyaron un proceso de descentralización como marco institucional conveniente para la expresión política de la insurgencia dentro de las instituciones.
} 
mas estatales. Abrir los espacios institucionales a los movimientos sociales para que participen de las políticas descentralizadas es el objetivo político manifestado por la estrategia incluyente (Restrepo, 2002).

La inserción institucional del movimiento guerrillero es el mayor reto del nuevo diseño institucional. La insubordinación social y la insurgencia guerrillera tienen un asentamiento en realidades territoriales específicas. Por lo tanto, un componente de la estrategia de paz es la apertura de espacios para que puedan insertarse, en el lugar donde están, en la administración de las políticas, bienes y servicios por ellos reclamados.

La inclusión social debería conducir a la legitimidad política del Estado ${ }^{10}$ y del régimen electoral (Calderón, 1987). Reducir la abstención electoral es la esperanza depositada en la descentralización política en un país con tasas crónicas de abstención superiores a $50 \%$ del censo electoral. Se presume que los ciudadanos en las localidades tendrían mayor estímulo en acudir a las urnas para decidir las mayorías de gobierno y sancionar o refrendar grupos y candidatos políticos (Gaitán y Moreno, 1992).

Desde los reformadores políticos, por lo tanto, la descentralización es una estrategia de legitimación de las instituciones y del régimen político y parte estratégica de los cambios políticos necesarios para consolidar la paz.

\section{Las clases políticas locales y su reproducción a través de la descentralización}

La arremetida neoliberal y el proceso de globalización achican el espacio de los políticos profesionales. Mediante las privatizaciones, pierden el manejo de empresas, presupuestos, contratos, empleos y políticas estatales. La desregulación de las relaciones laborales y el debilitamiento de los sindicatos disuelve las relaciones entre la burocracia sindical y la burocracia política, disminuyendo el espacio político a los unos y los otros. Mediante la apertura financiera, comercial y productiva, la lógica privada de las transnacionales se impone de manera creciente sobre las regu-

${ }^{10}$ Dentro de la estrategia de legitimidad se destaca el programa de reconciliación entre el Estado y las comunidades, conocido como Plan Nacional de Rehabilitación (PNR), el cual se extendió durante tres periodos presidenciales: Belisario Betancur (19821986), Virgilio Barco (1986-1990) y César Gaviria (1990-1994). La Red de Solidaridad Social del presidente Ernesto Samper (1994-1998) integró programas, estructuras y parte de la burocracia del PNR en el nuevo programa de lucha contra la pobreza. 
laciones nacionales, el derecho estatal y los pactos sociales y políticos internos son socavados (Restrepo, 1994a; Ahumada, 1996).

La política social es uno de los pocos terrenos en los que se mantiene la 'soberanía' de los Estados y por ende, las competencias de las clases políticas. ${ }^{11}$ La pugna por la descentralización de las finanzas públicas y de las competencias en materia social caracteriza las relaciones entre los poderes políticos territoriales y nacionales. Del manejo de los gobiernos locales está dependiendo cada vez más la conformación, ampliación y reproducción no sólo de las clases políticas, sino de las agremiaciones partidistas. Es decir, en la medida en que la crisis política del Frente Nacional conduce a la disolución de los partidos nacionales, se fortalecen las agremiaciones partidistas territoriales (Borja, 1999).

La Federación Colombiana de Municipios y la Conferencia de Gobernadores son las organizaciones gremiales de los municipios y departamentos, las cuales conducen las negociaciones políticas con el nivel central de gobierno, a partir de una lógica que supera las alineaciones partidistas nacionales. Alcaldes y gobernadores de movimientos y partidos diferentes a los nacionales manejan un tercio de los municipios y departamentos del país. Seis gobernadores de los departamentos del sur del país plantean la construcción de una región administrativa y de planeación como paso previo antes de la conformación de una región política, con autoridades y rentas propias. ${ }^{12}$

Estos ejemplos demuestran la importancia que la vida local posee en la construcción del poder político ejercido sobre las localidades, las regiones y la nación misma. El proceso de la descentralización es el resultado de la insurgencia de los poderes locales (Leal y Dávila, 1990) y a la vez aumenta la recomposición política con base en intereses territoriales.

Las clases políticas territoriales ganadoras son aquellas que están conectadas al mercado mundial, consolidan alianzas estra-

${ }^{11}$ Soberanía relativa, porque los efectos sociales de la apertura, las privatizaciones y la desregulación de las relaciones laborales conducen al aumento de la pobreza y la marginalidad, disminuye los ingresos de los trabajadores, acrecienta la concentración del ingreso y hacen de la política social un negocio para los intermediarios financieros. Las políticas y sus efectos son globales, así como las políticas sociales focalizadas y de remiendo, cuya operación por los Estados nacionales y locales son el margen de soberanía delegada.

${ }^{12}$ Los gobernadores del departamento del Tolima, Huila, Nariño, Cauca, Caquetá y Putumayo plantean la región del sur dentro de una segunda fundación de la república de carácter federal. Importa señalar que ejercen una diplomacia internacional alterna a la del gobierno nacional, en particular respecto al tratamiento de los cultivos con usos ilícitos: el denominado Plan Colombia del gobierno de los Estados Unidos. 
tégicas con el sector privado local y conducen las negociaciones para atraer capitales públicos y privados, nacionales y extranjeros a sus regiones. Las clases políticas perdedoras se encuentran en regiones deprimidas por el desmonte del Estado, la quiebra de sus empresas y las desinversiones de capital.

En los procesos de apertura y globalización, las regiones ganadoras y las perdedoras están pujando por mayores grados de autonomía frente a la clase política nacional. Buscan consolidar poder local, articular políticas de crecimiento y legitimidad con características propias e imprimir un sello 'regional' al ejercicio de gobierno. ${ }^{13}$

En este sentido, para las clases políticas locales la descentralización es un refugio ante el debilitamiento del Estado-Nación, una oportunidad de inserción en los asuntos privatizados y en la búsqueda de nuevas inversiones en el ámbito regional, y un bastión a partir del cual negocian espacios de poder con el nivel central del régimen político y el Estado.

\section{Los movimientos sociales y la apropiación territorial de la democracia}

Los nuevos movimientos sociales tienen características que los diferencian de las organizaciones de asalariados. Su organización surge de identidades territoriales y no de la unidad del trabajo llámese ésta fabrica u oficina-, sino a partir del barrio, la vereda, el municipio o la región (Restrepo, 1994b).

También se caracterizan por reclamar fundamentalmente servicios y políticas sociales de salud, educación, vías, saneamiento básico, acueducto y alcantarillado (Santana, 1978). A su vez, las reivindicaciones fundamentales del sindicalismo versan sobre la seguridad del empleo, los salarios y las condiciones laborales y se relegan las otras demandas a lugares marginales de los pliegos de petición y los pactos colectivos. De tal manera, mientras el sindi-

${ }^{13}$ Los sucesivos alcaldes de la capital de la República, Bogotá, han luchado por mayores grados de autonomía frente a la nación, a la vez que reclaman una disminución de las transferencias que la ciudad aporta a las regiones más deprimidas del país por la vía de los impuestos nacionales. Los gobernadores de departamentos de gran desarrollo capitalista como Antioquia y Valle solicitan mayor autonomía para la política económica y tributaria, y empiezan también a ejercer una diplomacia patronal propia en el ámbito internacional. Los gobernadores del sur, azotados por el narcotráfico, los paramilitares, la guerrilla y la depresión económica, pugnan por una solución política negociada de carácter regional y un modelo de desarrollo alternativo, es decir, con base en la economía campesina y los pequeños y medianos propietarios regionales. 
calismo se mueve en el campo de la producción, los nuevos movimientos sociales lo hacen en el de la circulación.

Las nuevas demandas populares no se limitan a pedir más política social, a menores precios y de mejor calidad: exigen la participación de los usuarios en las instituciones, políticas y proyectos, así como en la administración territorial que presta los bienes y servicios. Se trata de un rasgo bastante diferente al movimiento sindical, el cual reivindica al Estado y al mercado la mejoría de sus condiciones salariales y de trabajo. Las organizaciones gremiales de los asalariados mantienen una externalidad y una no-responsabilidad con el Estado en cuanto a las políticas públicas y con el mercado respecto al manejo de las empresas. En cambio, los nuevos movimientos sociales son esencialmente participativos (Restrepo, 2002).

De esta manera, los nuevos movimientos sociales transforman la práctica política del campo popular. No se trata únicamente de exigir la mejoría en las condiciones de vida ante el mercado y el Estado, sino de la apropiación territorial del poder, tanto referido a la administración pública y sus políticas, como a las posibilidades de competir en el mercado, público y privado, por el manejo de los recursos (Fals, 2000; Restrepo, 2002).

Los movimientos sociales han sido un actor fundamental dentro del proceso de descentralización, aun cuando no hayan participado directamente en la redacción de ninguna de las definiciones normativas fundamentales. Sin embargo, debe observarse que los nuevos movimientos sociales tuvieron un auge creciente y ascendente en todas las décadas de los 70 y 80 : más personas movilizadas, más municipios cubiertos, mayor fuerza de reivindicación alrededor de la política social y la participación territorial en las políticas públicas.

La descentralización de la política social corresponde a lo reivindicado por los movimientos sociales. El tercer encuentro nacional de movimientos cívicos, reunidos en Bogotá en octubre de 1983, afirmó que para solucionar la crisis política del país se requería de la elección popular de alcaldes y gobernadores, planes de desarrollo locales, cabildos abiertos y participación de los usuarios en la administración de las empresas públicas. Estas cinco propuestas se convirtieron en leyes de la República a partir de 1986. Por lo tanto, aun cuando los movimientos sociales no participen en la hechura de la política y de las normas, la descentralización es una respuesta a la reconstitución de la expresión del campo popular (Restrepo, 1992). 
La descentralización es una respuesta del régimen político en crisis, mediante la cual construye una nueva institucionalidad que potencia mecanismos de incorporación de los nuevos movimientos sociales dentro de los espacios y prácticas burocráticas. También pretende la localización del descontento social (Moncayo, Restrepo y Rojas, 1989).

\section{La guerrilla y la consolidación de hegemonías militares en los territorios}

Históricamente, el movimiento guerrillero levantó una plataforma de conquista del poder a escala nacional, de destrucción del Estado capitalista y el régimen político bipartidista. A cambio, propuso una alternativa más o menos socialista, comunista, maoísta o nacionalista, pero siempre de carácter nacional, estatal y centralizado.

Esta postura cambió desde finales de la década de los ochenta, a partir del proceso de descentralización. Antes, el movimiento guerrillero rechazó de manera unánime la participación en las contiendas electorales porque, según su análisis, confundían al pueblo sobre los verdaderos mecanismos a partir de los cuales se definía la lucha de clases y la dominación capitalista. Sin embargo, los movimientos insurgentes que han dejado las armas desde comienzos de la década de los noventa se han volcado sobre la vida política municipal y departamental. ${ }^{14}$ Más de cuatrocientos guerrilleros reinsertados han sido elegidos en los concejos municipales, según las estadísticas del Programa para la Reinserción; también se han integrado a la lucha por las alcaldías y los planes de desarrollo local, o sea a la participación política en el escenario local. ${ }^{15}$

Este cambio de política se explica porque la guerrilla tiene un poder militar estructurado sobre el eje de la conquista del poder nacional, pero se convirtió en un poder territorial, que de una u otra manera, presiona, chantajea o incide sobre las actividades de la economía pública y privada, la política y las institu-

${ }^{14}$ El Movimiento 19 de abril (M19), el Partido Revolucionario de los Trabajadores (PRT), el Quintín Lame, el Ejército Popular de Liberación (EPL) y una fracción del Ejército de Liberación Nacional (ELN).

${ }^{15}$ Antonio Navarro, el segundo de la jerarquía militar del M19, ha sido el más prestigioso de los reinsertados. Ministro de Salud en 1990, co presidente de la Asamblea Nacional Constituyente en 1991, posteriormente alcalde de su ciudad natal, Pasto, congresista por Bogotá y actualmente el senador de la República con mayor votación en el país. 
ciones locales. Los movimientos guerrilleros activos: Fuerzas Armadas de Colombia (FARC) y Ejército de Liberación Nacional (ELN), principalmente, se están convirtiendo en una fuerza cuasi-hegemónica en ciertos territorios, a tal punto que se comportan como proto-Estados. Las ciernes de un Estado en los territorios guerrilleros se basan en el dominio militar permanente, la garantía de la seguridad a las personas, la implementación de códigos híbridos de justicia y la presión tributaria sobre la población, los negocios privados y la administración pública.

En esta perspectiva, el proceso de descentralización -al transferir recursos y funciones y legitimar el poder electoral de los mandatarios-, convierte la conquista del poder local en un asunto importante y estratégico para el movimiento guerrillero. Mediante la conquista de los poderes locales, usufructúa las funciones y los recursos descentralizados y se legitima a través del manejo, presión y apropiación sobre tales recursos y funciones.

En los últimos diez años, el movimiento guerrillero ha multiplicado en más de dos veces los frentes de guerra, la cantidad de hombres en armas, el control de los territorios y su capacidad económica. Se ha transitado de un movimiento guerrillero de carácter 'foquista', que tenía actividades de defensa y reacción contra el ejército y la policía, a un movimiento guerrillero de carácter ofensivo; que de posiciones móviles ha pasado, en muchas partes, a un poder armado de control territorial sobre las poblaciones que viven en esos territorios, las actividades sociales y económicas, las instituciones y las políticas estatales. En Colombia, se está transitando de un movimiento guerrillero hacia batallones armados que en buena medida empiezan a comportarse como ejércitos alternos, sobre todo las FARC.

Por otra parte, el movimiento guerrillero ha pasado de zonas rurales relativamente marginales hacia otras de mayor importancia estratégica y geopolítica, zonas urbanas de mayor poblamiento y actividad económica, alrededor de la malla de comunicaciones, carreteras, puentes, circuitos de tránsito del agua, ecosistemas estratégicos e infraestructura energética.

El desarrollo de la guerrilla tiende a quebrantar el control que el poder central y el bipartidismo tenían sobre los procesos locales; disputa a escalas local y regional el control del electorado y de los procesos económicos, políticos, sociales e institucionales. El auge del movimiento guerrillero es otro factor que debilita el presidencialismo, el centralismo y el Estado-Nación; exacerba las luchas locales por el poder y acrecienta la apropia- 
ción de los procesos locales en un escenario de negociación o disputa de alternativas al poder nacional.

\section{Los narcotraficantes y la subordinación de los poderes locales}

A partir del tráfico de drogas surge de manera vertiginosa una nueva élite económica que llega a enfrentarse al Estado mediante la violencia, compite con las jerarquías nacionales y locales del bipartidismo por el control sobre el electorado, disputa a tradicionales ramas de la actividad económica ${ }^{16}$ y pugna por el control de los aparatos del Estado, la justicia, la opinión pública y las instituciones.

De esta manera, el tráfico ilegal de drogas también tiende a quebrantar la unidad del proyecto político del Frente Nacional, de las élites políticas y de los sectores económicos que lo fundaron. El narcotráfico se coloca en el centro de la disputa del poder económico, político e institucional que se organizó a través del centralismo y el bipartidismo. Exacerba también la lucha por el control de los territorios, tanto a escala regional como nacional.

El control de los territorios es fundamental para el tráfico de estupefacientes porque el lugar de la siembra, los corredores de seguridad y las vías de comunicación son sitios para el 'blanqueo' y el 'lavado' de los recursos ilícitos y porque les permite convertir grandes cantidades de liquidez monetaria ilegal en apropiación de activos legales.

El control territorial ejercido se extiende al control político, de la policía, el ejército, las comunicaciones y las personas. Es por ello que el gobierno nacional, en su lucha contra el narcotráfico, creó brigadas móviles especializadas que operan sin informar a las Fuerzas Armadas o a la policía acantonada en los municipios, ni tampoco a las autoridades políticas locales. Las fuerzas represivas extraterritoriales han producido resultados mucho más efectivos, lo cual refleja la lucha de un sector del Estado contra la apropiación del poder territorial por el narcotráfico.

${ }^{16}$ Los narcotraficantes intentaron, con Carlos Lehder, conformar un partido político propio, pero desistieron. Su expresión partidista se ha volcado sobre las estructuras de los partidos tradicionales. Las relaciones económicas con los sectores de negocios tradicionales ha combinado la fusión de intereses con la competencia, hasta la substitución de unos por otros por la vía de la compra o la amenaza. 


\section{De la guerra sucia a los ejércitos paramilitares}

El movimiento armado paramilitar resulta de la confluencia de seis causas. Es una prolongación de la criminalización institucional de la protesta y de los sectores populares $;{ }^{17}$ concreta, en este sentido, el paso de la guerra sucia a la guerra contra la insubordinación social. Por otra parte, es la respuesta violenta de los terratenientes ante la presión campesina y de la guerrilla que resulta de la ausencia de políticas de reforma agraria y de las falencias del ejército nacional. También, provienen de un clamor de la población, fundamentalmente de pueblos pequeños y medianos, ante la presión y los desmanes de la guerrilla, porque brindan la seguridad que las fuerzas regulares del Estado no garantizan. Son también el mecanismo que reemplaza el dominio que sobre la sociedad ejercía el orden bipartidista del Frente Nacional y garantizan el reino de hegemonías políticas totales. Además, el movimiento paramilitar es el brazo armado de la pugna por el control de áreas económicas estratégicas actuales y potenciales. Por último, desde sus inicios los paramilitares ejercen funciones de ejército privado de los narcotraficantes.

Con el auge del movimiento insurgente y contrainsurgente, los paramilitares tienden hacia la conformación de una fuerza político-militar nacional. Se convierten, de tal manera, en un actor específico con estructura, financiación y agenda programática propias. Hasta ahora no han requerido la conformación de un partido político nuevo, sino que han colonizado las estructuras de los partidos tradicionales al punto de reclamar 35\% de la representación en el Congreso de la República surgido de las elecciones de marzo de 2002.

El auge de los ejércitos privados paramilitares y el movimiento guerrillero son la demostración más clara de la disolución del Estado colombiano. Los sectores económicos y políticos locales, que promueven, financian y encubren a los paramilitares, no confían más en el uso exclusivo de las fuerzas y mecanismos regulares del Estado para la defensa y promoción de sus intereses. Acuden a la financiación privada de su seguridad e intereses y con ello disuelven el Estado de derecho.

$\mathrm{Al}$ igual que la guerrilla y el narcotráfico, los paramilitares tienen una estrategia basada fundamentalmente en la apropia-

\footnotetext{
${ }^{17}$ En Colombia, la tendencia a criminalizar la protesta social es una práctica regular y no circunscrita a casos críticos o marginales.
} 
ción militar de territorios, pugnan por la subordinación del conjunto de la economía pública y privada y de los movimientos, líderes y organizaciones sociales a la lógica de la guerra, la disciplina y la jerarquía militar (Pedraza et al., 2000). La actividad paramilitar es una estrategia de apropiación para-estatal de los territorios por los ejércitos contrainsurgentes.

De tal manera, los paramilitares también contribuyen a debilitar el control central del Estado sobre los procesos políticos y militares locales, exacerban la confrontación armada como medio fundamental de resolución de las disputas por el control político local, y constituyen una fuerza político-militar regional con capacidad de incidencia sobre las perspectivas nacionales y territoriales de la guerra o la paz.

La guerra en Colombia nunca ha sido nacional: siempre ha sido territorial. La guerra se despliega en territorios en disputa entre varias fuerzas con pretensiones hegemónicas. En el periodo conocido bajo el calificativo de La Violencia (1948-1953), los muertos, las masacres, los desaparecidos y las torturas ocurrían en los municipios donde se enfrentaban liberales y conservadores para sumar mayorías nacionales (Palacios, 1995). De la misma manera, la guerra actual está en los municipios donde no hay hegemonía de uno u otro bando, o en las fronteras de las hegemonías entre unos y otros. La guerra es por el control de territorios específicos, en tanto bastiones para negociar el equilibrio de fuerzas en el ámbito nacional.

Esto explica las contradicciones militares actuales entre las FARC y el ELN. Las FARC tienen un mapa de expansión colonizadora de territorios que obedece a una estrategia de ocupación militar nacional. En los departamentos de Santander, Sucre, Urabá, Antioquia o Sur de Bolívar, la coexistencia con el ELN conduce a inevitables enfrentamientos armados entre ellos. La guerra en Colombia ya no es sencillamente una guerra de guerrillas combinada con una guerra sucia, sino una guerra de múltiples actores que intentan controlar militarmente los territorios, sus territorios.

\section{Conclusión}

De la somera revisión de las estrategias de diferentes actores ante el proceso de descentralización y el poder local, se concluye que neoliberales, reformadores políticos, nuevos movimientos sociales, narcotráfico, guerrilla y paramilitares tienen hoy en el centro de su estrategia la apropiación de los poderes regionales y terri- 
toriales. En Colombia existe una incapacidad de hegemonía nacional por parte de cualquiera de las fuerzas y racionalidades anteriormente mencionadas y una lucha entre hegemonías parciales que pugnan por el control de territorios, instituciones, políticas y funciones estatales específicas. Las instituciones se están resquebrajando porque los poderes políticos, sociales y militares subordinan la lógica de las instituciones, la economía pública y privada en los territorios. Los actores armados tienden a comportarse como cuasi-estados y la guerra se concentra en la apropiación territorial del poder. Por lo tanto, entre más avance y se prolongue la guerra, más tenderá el país a estar compartido por fuerzas militares hegemónicas en cada una de las regiones, con capacidad de controlar, o por lo menos de incidir, sobre la actividad social, política y económica, institucional y privada.

\section{Bibliografía}

Ahumada, Consuelo (1996), El modelo neoliberal y su impacto en la sociedad colombiana, El Áncora Editores, Bogotá.

Banco Mundial (1993), Invertir en salud. Informe sobre el desarrollo mundial 1993, Banco Mundial, Washington.

Beck, Ulrich (1998), ¿¿Qué es la globalización? Falacias del globalismo, respuestas a la globalización, Ediciones Paidós Ibérica, Barcelona.

Bird, Richard (1981), Finanzas intergubernamentales en Colombia. Informe final, Departamento Nacional de Planeación, Bogotá.

Borja, Miguel (1999), Estado, sociedad y ordenamiento territorial en Colombia, Editorial Cerec, Bogotá.

Calderón Rivera, Mario (1987), Un nuevo municipio, un nuevo país, Banco Central Hipotecario (BCH), Bogotá.

Castañeda, Sonia, Darío González y Augusto Mares (comps.) (2000), Las claves territoriales de la guerra y la paz. Mandato ciudadano por la paz, la vida y la libertad, Bogotá Editor, Bogotá. 
Castro, Jaime (1984), La democracia local, Editorial Oveja Negra, Bogotá.

— (1998), Descentralizar para pacificar, Editorial Ariel, Bogotá.

Cuervo, Luis Mauricio y Josefina González (1998), "Régimen de servicios públicos domiciliarios. Primer tiempo: Tecnocracia $=1$, Autonomía local $=0$ ", La investigación regional y urbana en Colombia. Desarrollo y territorio 1993-1997, Carlos Valencia Editores, Bogotá, pp. 456-472.

Fals Borda, Orlando (2000), Acción y espacio. Autonomías en la nueva República, Tercer Mundo Editores / Universidad Nacional de Colombia, Bogotá.

Gaitán, Pilar y Carlos Moreno (1992), Poder local. Realidad y utopía de la descentralización en Colombia, Tercer Mundo editores, Bogotá.

González, Jorge Iván (1994), “Un ordenamiento territorial de corte fiscalista", Diez años de descentralización. Resultados y perspectivas, Fundación Friedrich Ebert de Colombia / Fescol, Bogotá, pp. 99-127.

Jaramillo, Iván (1994), El futuro de la salud en Colombia. Politica social, mercado y descentralización, Fundación Friedrich Ebert de Colombia - FESCOL / Fundación Corona / Fundación para la Educación Superior - FEs / Fundación Restrepo Barco - FRB, Bogotá.

Leal, Francisco y Andrés Dávila Ladrón de Guevara (1990), Clientelismo. El sistema político y su expresión regional, Tercer Mundo Editores / Universidad Nacional de Colombia, Bogotá.

Maldonado, María Mercedes (1998), "Municipalización y privatización: ¿procesos divergentes?”, La investigación regional y urbana en Colombia. Desarrollo y Territorio 19931997, Carlos Valencia Editores, Bogotá, pp. 473-488. 
Moncayo, Víctor Manuel, Darío I. Restrepo y Fernando Rojas (1989), "Las políticas de descentralización político-administrativa en Colombia: entre la modernización del Estado y la legitimidad del régimen", Centralización/descentralización del Estado y actores territoriales, Clacso, Buenos Aires.

Ochoa, Doris y Darío I. Restrepo (1997), "Balance político de la descentralización”, Descentralización, desarrollo institucional y democratización, Escuela Superior de Administración Pública - ESAP / Ministerio del Interior / Fondo para la Participación Ciudadana, Bogotá, pp. 77-131.

Palacios, Marco (1995), Entre la legitimidad y la violencia. Colombia, 1875-1994, Grupo Editorial Norma, Bogotá.

Pedraza, Betty, Luz Margot Pulido y Ana Luz Rodríguez (2000), Bajo el fuego. Tres tendencias de participación en zonas de conflicto, Fundación para la Participación Comunitaria Parcomún / Acción Ecuménica Sueca - Diakonía, Bogotá.

Restrepo, Darío I. (1992), Descentralización y neoliberalismo, Fondo Editorial CEIR - Realidad Municipal, Bogotá.

- (1994a), "Aspectos espaciales de la reestructuración: apertura y descentralización", Revista Latinoamericana de Estudios Urbanos - Eure, vol. xx, núm. 59, Instituto de Estudios Urbanos, Pontificia Universidad Católica de Chile, Santiago de Chile, pp. 93-109.

- (1994b), "Los desfases de la democracia”, Democracia formal y real, Instituto para el Desarrollo de la Democracia Luis Carlos Galán, Bogotá, pp. 173-221.

(1996), "Políticas sociales de la nueva era”, Globalización y Estado Nación, Escuela Superior de Administración Pública - ESAP, Bogotá, pp. 139-193.

_ (2000), "El mito de Sísifo o veinte años de pujanza descentralizadora en Colombia”, Reforma y Democracia, núm. 
17, Centro Latinoamericano de Administración para el Desarrollo - CLAD, Caracas, pp. 77-127.

- (2001), "Dimensión espacial y política de la reestructuración capitalista", Economía, Sociedad y Territorio, vol. III, núm. 9, El Colegio Mexiquense, Zinacantepec, México, pp. 93-127.

— (2002), “Las prácticas participativas: entre la socialización y la privatización de las políticas públicas”, Enlaces y rupturas. Experiencias de participación representativas de una década en Colombia, Fundación para la Participación Comunitaria - Parcomún / Acción Ecuménica Sueca Diakonía, Bogotá, pp. 93-135.

Rosas Vega, Gabriel (coord.) (1997), El saneamiento fiscal, un compromiso de la sociedad. Informe final de la Comisión de Racionalización del Gasto y de las Finanzas Públicas, Ministerio de Hacienda y Crédito Público, Bogotá.

Santamaría, Ricardo y Gabriel Silva (1984), Proceso politico en Colombia. Del Frente Nacional a la apertura democrática, Editorial Cerec, Bogotá.

Santana, Pedro (1978), Desarrollo regional y paros cívicos en Colombia, Centro de Investigación y Educación PopularCinep, Bogotá.

Velázquez Cock, Álvaro (1986), Comisión de Gasto Público. Informe final, Ministerio de Hacienda y Crédito Público, Bogotá.

Wiesner Durán, Eduardo (1992), Colombia: Descentralización y federalismo fiscal. Informe final de la Misión para la Descentralización, Departamento Nacional de Planeación, Bogotá. 
